\title{
A produção científica mundial sobre a tecnologia bioflocos na tilapicultura como
}

\section{propulsora do desenvolvimento sustentável}

\author{
World scientific production on biofloc technology in tilapiculture as a driver of sustainable \\ development
}

La producción científica mundial sobre la tecnología de biofloc en la tilapicultura como motor del desarrollo sostenible

Recebido: 18/04/2021 | Revisado: 28/04/2021 | Aceito: 04/05/2021 | Publicado: 16/05/2021

\author{
Sidnei Gregório Tavares \\ ORCID: https://orcid.org/0000-0002-6390-8150 \\ Universidade Estadual do Oeste do Paraná, Brasil \\ E-mail: sidigt@yahoo.com.br \\ Susã Sequinel de Queiroz \\ ORCID: https://orcid.org/0000-0001-9484-7584 \\ Universidade Estadual do Oeste do Paraná, Brasil \\ E-mail: susasqueiroz@hotmail.com \\ Geysler Rogis Flor Bertolini \\ ORCID: https://orcid.org/0000-0001-9424-4089 \\ Universidade Estadual do Oeste do Paraná, Brasil \\ E-mail: geysler.Bertolini@unioeste.br. \\ Adriana Maria de Grandi \\ ORCID: https://orcid.org/0000-0002-5917-0536 \\ Universidade Estadual do Oeste do Paraná, Brasil \\ E-mail: adriana.grandi@unioeste.br \\ Mariana Lins Rodrigues \\ ORCID: https://orcid.org/0000-0003-4957-9626 \\ Universidade Estadual do Oeste do Paraná, Brasil \\ E-mail: lins.mariana@hotmail.com \\ Altevir Signor \\ ORCID: https://orcid.org/0000-0002-4659-6466 \\ Universidade Estadual do Oeste do Paraná, Brasil \\ E-mail: altevir.signor@gmail.com
}

\begin{abstract}
Resumo
O objetivo deste estudo de revisão foi avaliar a sustentabilidade econômica, social e ambiental da biotecnologia bioflocos no cultivo de tilápia do Nilo Oreochromis niloticus. Com uma revisão sistemática, utilizou-se como metodologia os detalhamentos dos critérios de exclusão e inclusão adotados para a seleção da amostra e análise dos conteúdos das publicações. Os artigos utilizados neste estudo foram pesquisados nas bases Scopus e Web of Science. Foi utilizada a metanálise, optando-se pela natureza mista, ou seja, qualitativa e quantitativa de artigos publicados nas revistas científicas no período de 2008 a 2021. Constatou-se que a avaliação econômica, social e ambiental que contempla o desenvolvimento sustentável encontra-se em fase inicial de abordagem, face ao número de artigos que contemplam o assunto no período analisado. Os estudos envolvendo a biotecnologia de bioflocos contemplados nessa metanálise pertencem especialmente a ordem técnica, seguida da sustentabilidade da tecnologia empregada e aspectos positivos com relação ao âmbito econômico. Não obstante, há um déficit na abordagem dos aspectos sociais envolvidos com a aplicação desta biotecnologia.
\end{abstract}

Palavras-chave: Piscicultura; Bioflocos; Sustentabilidade; Desenvolvimento tecnológico; Agronegócio.

\begin{abstract}
The purpose of this review study was to evaluate the economic, social and environmental sustainability of biofloc biotechnology in the cultivation of Nile tilapia Oreochromis niloticus. With a systematic review, it was used as methodology the details of the exclusion and inclusion criteria adopted for the selection of the sample and analysis of the content of the publications. The articles used in this study were searched on the Scopus and Web of Science databases. As for the analysis, the meta-analysis was used, opting for the mixed nature, that is, qualitative and quantitative of articles published in scientific journals from 2008 to 2021. It was found that the economic, social and environmental assessment that contemplates sustainable development is found. if in the initial phase of approach, in view of the number of articles that contemplate the subject, in the analyzed period. The studies carried out using the biofloc technology belong mainly to the technical order, followed by the sustainability of the technology used,
\end{abstract}


positive aspects in relation to the economic scope, however, there is a deficit in the approach of the social aspects involved with the application of this biotechnology.

Keywords: Fish farming; Bioflocs; Sustainability; Technological development; Agribusiness.

\section{Resumen}

El propósito de este estudio de revisión fue evaluar la sostenibilidad económica, social y ambiental de la biotecnología de biofloc en el cultivo de tilapia del Nilo Oreochromis niloticus. Con una revisión sistemática, se utilizó como metodología el detalle de los criterios de exclusión e inclusión adoptados para la selección de la muestra y análisis del contenido de las publicaciones. Los artículos utilizados en este estudio se buscaron en las bases de datos Scopus y Web of Science. En cuanto al análisis, se utilizó el metaanálisis, optando por el carácter mixto, es decir, cualitativo y cuantitativo de los artículos publicados en revistas científicas de 2008 a 2021. Se encontró que la evaluación económica, social y ambiental que contempla el desarrollo sostenible se encuentra, si en la etapa inicial de abordaje, en vista de la cantidad de artículos que contemplan el tema, en el período analizado. Los estudios realizados utilizando la tecnología biofloc pertenecen especialmente al orden técnico, seguidos de la sostenibilidad de la tecnología utilizada, aspectos positivos en relación al ámbito económico, sin embargo, existe un déficit en el abordaje de los aspectos sociales involucrados con la aplicación. de esta biotecnología.

Palabras clave: Piscicultura; Bioflocs; Sustentabilidad; Desarrollo tecnológico; Agroindustria.

\section{Introdução}

Constantemente enfrenta-se o desafio de crescer em um mundo com recursos limitados, trazendo a necessidade de refletir sobre o comportamento humano e formas de exploração do mundo para buscar garantir as necessidades das próximas gerações. Existe uma possibilidade de que a população humana atinja cerca de 10 bilhões até 2050, o que gera dúvidas sobre como será alimentada toda essa população. Para alimentar todo esse contingente de pessoas estima-se que a produção de alimentos deverá aumentar 50\% globalmente (FAO, 2019).

A nutrição humana é baseada principalmente em água, carboidratos, proteínas, gorduras, minerais e vitaminas. Esses nutrientes podem ser fornecidos a partir de vegetais e animais, contudo, para produção dos alimentos, muitos recursos essenciais são utilizados, como água, solo e fontes de energia. No sistema de produção de pescados, por exemplo, como proteína animal saudável e completa nutricionalmente, a tecnologia empregada depende essencialmente da água. Em face disso, tem-se buscado o aprimoramento dos sistemas intensivos, que visam além da alta produtividade, a redução dos efluentes gerados, o reuso das águas de cultivo e a menor disseminação de patologias no ambiente.

A Tecnologia Bioflocos (BFT) é considerada uma técnica sustentável ou uma tecnologia amigável para o meio ambiente, reduzindo as trocas de água a zero nos sistemas de aquicultura (Avnimelech, 2007; Azim e Little, 2008). O sistema BFT é uma tecnologia capaz de desenvolver um processo produtivo dentro do quadro esperado pelo desenvolvimento sustentável na aquicultura, não apenas na visão econômica, mas também social e ambiental.

Neste contexto, o objetivo deste estudo de revisão científica foi avaliar a sustentabilidade econômica, social e ambiental da biotecnologia de bioflocos para tilápia do Nilo, Oreochromis niloticus, contida na produção científica mundial.

\section{Conceito de bioflocos, relação com meio ambiente e aplicabilidade do sistema}

O sistema de bioflocos é considerado ainda um sistema de troca mínima ou até mesmo zero de água, o que lhe confere as vantagens de manter a temperatura e as flutuações de calor (Crab et al. 2009). Além disso, esse sistema promove a metabolização dos compostos nitrogenados, mesmo quando a matéria orgânica e a demanda bioquímica de oxigênio no ambiente de cultivo são altas (Avnimelech, 2015).

Pérez-Fuentes et al. (2016), defendem que o sucesso e a permanência do setor de aquicultura dependem da implementação de tecnologias sustentáveis e favoráveis ao meio ambiente. Além disso, destacaram que a tecnologia BFT otimiza a utilização de energia e recursos durante a produção, de modo que os resultados contribuem de forma significativa para o setor. 
Segundo Bossier e Ekasari (2017) a aplicação da tecnologia BFT oferece benefícios na melhoria da produção da aquicultura, a qual pode contribuir para a consecução de metas de desenvolvimento sustentável. Esta tecnologia pode resultar em maior produtividade com menor impacto para o meio ambiente. Além disso, os sistemas podem ser desenvolvidos e realizados em integração com a produção de outros alimentos, promovendo sistemas integrados produtivos e visando produzir mais alimentos, os quais podem ser provenientes, inclusive, da mesma área de terra com menos insumos. Entretanto, os autores afirmam ainda que a tecnologia está em fase preliminar.

As vantagens da tecnologia na aquicultura têm sido bem documentadas, o que inclui baixo consumo de alimento artificial e água (econômico), menor risco de introdução de patógenos e doenças, maior biossegurança, maior crescimento e sobrevivência e, portanto, maior produção aquícola (Otoshi et al. 2009; Crab et al., 2009; Samocha et al., 1998, 2007; Krummenauer et al., 2011; Pérez-Fuentes et al., 2013). Em contrapartida, há um valor agregado ao consumo de energia elétrica, que será insumo de uso contínuo nesse modelo produtivo (Pasco, 2015).

Ahmad et al. (2017) afirmam que uma série de características benéficas está associada à tecnologia BFT, como 10 a $20 \%$ do potencial de ganho de alimento estimado pela aplicação da tecnologia quando comparado a sistemas tradicionais de cultivo (Crab et al., 2007; De Schryver et al., 2008). Este aumento foi baseado na recirculação interna de nutrientes através da formação de nova biomassa microbiana, que foi subsequentemente utilizada como fonte de alimento pelos animais cultivados (Avnimelech, 2006). Ocorre ainda a melhoria da taxa de conversão alimentar pela utilização da alimentação natural in situ, reduzindo os impactos ambientais (Krummenauer et al. 2014). Nesse sentido, é possível caracterizar esse sistema como robusto, fácil de operar e economicamente viável (Crab et al. 2012).

\section{Metodologia}

As revisões sistemáticas são utilizadas por serem abrangentes e não tendenciosas em sua preparação. Os critérios adotados são divulgados para que outros pesquisadores possam repetir o procedimento. Revisões sistemáticas de boa qualidade são consideradas como tendo um dos melhores níveis de evidência para a tomada de decisão. Seguindo um método científico explícito e apresentando novos resultados, a revisão sistemática é classificada como contribuição original na maioria dos periódicos de pesquisa (Galvão \& Pereira, 2014).

Nesse estudo foi utilizada a análise que tem natureza qualitativa e quantitativa. A natureza quantitativa, segundo Fachin (2006), é aquela onde os dados são quantificados e mensurados. Quanto à abordagem qualitativa, Richardson (1999) menciona que se diferencia da quantitativa por não usar instrumentos estatísticos em sua análise. Assim, nem todos os dados são comprovados em números.

A análise da pesquisa se deu por meio da quantificação entre os autores, as palavras-chave, as revistas, a relevância científica, dentre outras. Já a análise qualitativa se deu por meio da percepção dos autores quanto às informações relevantes encontradas em cada um dos artigos selecionados.

Primeiramente, a identificação das definições operacionais nas construções teóricas sobre bioflocos em sistema intensivo de produção de tilápias se deu por meio de uma busca nas bases de dados Web of Science e na Scopus, até 10 de março de 2021, usando os seguintes termos de busca como critérios de inclusão: "biofloc", "bioflocs" e "biofloc niloticus". Os critérios de inclusão tiveram um caráter generalizado devido ao fato de ser um estudo novo. Como existem mais estudos da aplicabilidade da tecnologia do bioflocos para o cultivo de camarões e para outros sistemas de recirculação de água, no entanto, a pesquisa teve vários critérios de exclusão: "vannamei", "shrimp", "aquaponic", "raceway", "RAS- Recirculating aquaculture system", “common carp", "reproductive performance”, “polymer addition”, "penaeus monodon”, “catfish”, “cage systems", "DSW - distillery spent wash", "poly-beta-hydroxybutyric", "polycaprolactone", "inoculation", "labeo rohita" e "artigos incompletos". 
O uso desse refinamento no banco de dados da Web of Science (WOS) e na base de dados Scopus, utilizando os mesmos critérios de inclusão e exclusão, resultou na seleção de publicações em periódicos datados de 2008 a 2021 . O estudo concentra-se na análise de artigos com tema tecnologia de bioflocos para tilapicultura.

\section{Resultados e Discussão}

A partir do levantamento das publicações realizadas nos principais periódicos (Tabela 1), constatou-se que apenas 75 artigos pesquisaram temas relacionados a tecnologia de bioflocos para a tilápia (Oreochromis niloticus), o que pode ser considerado um índice intermediário, mas explicado, em parte, pelo fato de ser uma técnica que ainda está sendo testada.

Tabela 1. Periódicos que abordaram pesquisas sobre o tema "Bioflocos".

\begin{tabular}{|l|c|c|}
\hline \multicolumn{1}{|c|}{ Revista } & Instituição & Fator de impacto \\
\hline Acta Scientiarum & UEM & 0.300 \\
\hline Aquacultural Engineering & ELSEVIER & 2.638 \\
\hline Aquaculture & ELSEVIER & 3.224 \\
\hline Aquaculture Research & ISI JOURNAL CITATION & 1.748 \\
& REPORTS & \\
\hline Fish \& Shellfish Immunology & ELSEVIER & 3.298 \\
\hline Microbial Biotechnology & ISI JOURNAL CITATION & 5.328 \\
& REPORTS & \\
\hline North American Journal of Aquaculture & WILEY & 1.077 \\
\hline Aquaculture International & SPRINGER & 1.750 \\
\hline Revista Caatinga & UFERSA & 0.713 \\
\hline
\end{tabular}

Artigos selecionadas com base na Web of Science e na Scopus (2021). Fonte: Autores (2021).

Com a análise dos artigos escolhidos e sob a perspectiva do objetivo deste estudo, utilizou-se de sete (7) revistas localizadas em vários países, entre eles Brasil, China, Indonésia e Índia. A revista mais utilizada foi a Aquaculture, que contempla a maior parcela dos artigos selecionados. A Tabela 2 apresenta alguns dados dos artigos selecionados como: autores, ano de publicação, título da pesquisa, periódico e país onde o estudo foi feito. 
Tabela 2. Dados de artigos selecionados para o levantamento bibliográfico sobre sistema de bioflocos para tilápia do Nilo.

\begin{tabular}{|c|c|c|c|c|}
\hline Autor(es) & Ano & Título & Revista & País \\
\hline M.E. Azim; D.C. Little & 2008 & $\begin{array}{c}\text { The biofloc technology (BFT) in indoor tanks: } \\
\text { water quality, biofloc composition and growth } \\
\text { and well-being of Nile tilapia (Oreochromis } \\
\text { niloticus) }\end{array}$ & Aquaculture & $\begin{array}{l}\text { Reino } \\
\text { Unido }\end{array}$ \\
\hline $\begin{array}{l}\text { Guo-zhi Luo } \\
\text { Yoram Avnimelech; } \\
\text { Yun-feng Pan; } \\
\text { Hong-xin Tan. }\end{array}$ & 2013 & $\begin{array}{c}\text { Inorganic nitrogen dynamics in sequence batch } \\
\text { reactors using biofloc technology to treat } \\
\text { aquaculture sludge }\end{array}$ & $\begin{array}{l}\text { Aquacultural } \\
\text { Engineering }\end{array}$ & China \\
\hline $\begin{array}{l}\text { Julie Ekasari; } \\
\text { Deasy Angela; } \\
\text { Setiyo Hadi Waluyo; } \\
\text { Taufiq Bachtiar; } \\
\text { Enang Harris Surawidjaja; } \\
\text { Peter Bossier; } \\
\text { Peter De Schryver }\end{array}$ & 2014 & $\begin{array}{l}\text { The size of the biofloc determines the nutritional } \\
\text { composition and the recovery of nitrogen by } \\
\text { aquaculture animals }\end{array}$ & Aquaculture & Indonésia \\
\hline $\begin{array}{l}\text { Lina Long; } \\
\text { Jing Yang; } \\
\text { Yuan Li; } \\
\text { Chong Wu Guan; } \\
\text { Fan Wu. }\end{array}$ & 2015 & $\begin{array}{c}\text { Effect of biofloc technology on growth, } \\
\text { digestive enzymatic activity, hematology and } \\
\text { immune response of genetically improved } \\
\text { tilapia }\end{array}$ & Aquaculture & China \\
\hline $\begin{array}{l}\text { Julie Ekasari; } \\
\text { Dio Rheza Rivand; } \\
\text { Amalia Putri Firdausi; } \\
\text { Enang Harris Surawidjaja; } \\
\text { Muhammad Zairin Jr; } \\
\text { Peter Bossier. } \\
\text { Peter De Schryver }\end{array}$ & 2015 & $\begin{array}{l}\text { Biofloc technology positively affects Nile tilapia } \\
\text { (Oreochromis niloticus) larvae performance }\end{array}$ & Aquaculture & Indonésia \\
\hline $\begin{array}{l}\text { Scott B. Day; } \\
\text { Khalid Salie; } \\
\text { Henk B. Stander. }\end{array}$ & 2016 & $\begin{array}{l}\text { A growth comparison among three commercial } \\
\text { tilapia } \\
\text { species in a biofloc system }\end{array}$ & $\begin{array}{l}\text { Aquaculture } \\
\text { International }\end{array}$ & $\begin{array}{c}\text { África do } \\
\text { Sul }\end{array}$ \\
\hline $\begin{array}{l}\text { Song Ming Zhu; } \\
\text { Ming Ming Shi; } \\
\text { Yun Jie Ruan; } \\
\text { Xi Shan Guo; } \\
\text { Zhang Ying Ye; } \\
\text { Zhi Ying Han; } \\
\text { Ya Le Deng; } \\
\text { Gang Liu. }\end{array}$ & 2016 & $\begin{array}{c}\text { Applications of computational fluid dynamics to } \\
\text { hydrodynamic modeling in the recirculation } \\
\text { biocirculation tilapia rearing tank Technology } \\
\text { system }\end{array}$ & $\begin{array}{l}\text { Aquacultural } \\
\text { Engineering }\end{array}$ & China \\
\hline $\begin{array}{l}\text { Gabriel Bernardes Martins; } \\
\text { Fábio Tarouco; } \\
\text { Carlos Eduardo Rosa; } \\
\text { Ricardo Berteaux Robaldo. }\end{array}$ & 2017 & $\begin{array}{l}\text { The utilization of sodium bicarbonate, calcium } \\
\text { carbonate or hydroxide in biofloc system: water } \\
\text { quality, growth performance and oxidative stress } \\
\text { of Nile tilapia (Oreochromis niloticus) }\end{array}$ & Aquaculture & Brasil \\
\hline
\end{tabular}




\begin{tabular}{|c|c|c|c|c|}
\hline $\begin{array}{l}\text { Gabriel Francisco de } \\
\text { Oliveira Alves; } \\
\text { Arthur Francisco Araújo } \\
\text { Fernandes; Érika Ramos de } \\
\text { Alvarenga; } \\
\text { Eduardo Maldonado Turra; } \\
\text { Alexandre Benvindo de } \\
\text { Sousa; } \\
\text { Edgar de Alencar Teixeira. }\end{array}$ & 2017 & $\begin{array}{c}\text { Effect of the transfer at different moments of the } \\
\text { juvenile Nile tilapia (Oreochromis niloticus) to } \\
\text { the BioFloc system in formation }\end{array}$ & Aquaculture & Brasil \\
\hline $\begin{array}{l}\text { Gang Liu; Songming Zhu; } \\
\text { Dezhao Liu; Zhangying } \\
\text { Ye. }\end{array}$ & 2018 & $\begin{array}{l}\text { Effect of the } \mathrm{C} / \mathrm{N} \text { ratio on inorganic nitrogen } \\
\text { control and the growth and physiological } \\
\text { parameters of tilapias fingerlings, } \\
\text { Oreochromis niloticus reared in biofloc systems }\end{array}$ & $\begin{array}{l}\text { Aquaculture } \\
\text { research }\end{array}$ & China \\
\hline $\begin{array}{l}\text { Gang Liu; Zhangying Ye; } \\
\text { Dezhao Liu; Jian Zhao; } \\
\text { Elayaraja Sivaramasamy; } \\
\text { Yale } \\
\text { Deng, Songming Zhu. }\end{array}$ & 2018 & $\begin{array}{l}\text { Influence of stocking density on growth, } \\
\text { digestive enzyme activities, immune } \\
\text { responses, antioxidant of Oreochromis niloticus } \\
\text { fingerlings in biofloc systems }\end{array}$ & $\begin{array}{l}\text { Fish \& Shellfish } \\
\text { Immunology }\end{array}$ & China \\
\hline $\begin{array}{l}\text { Baoxin Cao; Godwin } \\
\text { Abakari; Guozhi Luo; } \\
\text { Hongxin Tan; Xia Wu. }\end{array}$ & 2019 & $\begin{array}{l}\text { Comparative analysis of nitrogen and } \\
\text { phosphorus budgets in a bioflocs } \\
\text { aquaculture system and recirculation } \\
\text { aquaculture system during overwintering } \\
\text { of tilapia (GIFT, Oreochromis niloticus) }\end{array}$ & $\begin{array}{c}\text { Aquacultural } \\
\text { Engineering }\end{array}$ & China \\
\hline $\begin{array}{l}\text { Lombardo García-Ríos; } \\
\text { Anselmo Miranda-Baezaa; } \\
\text { Maurício Gustavo Coelho- } \\
\text { Emerenciano; } \\
\text { José Alberto Huerta- } \\
\text { Rábago;, Pablo Osuna- } \\
\text { Amarillas. }\end{array}$ & 2019 & $\begin{array}{l}\text { Biofloc technology (BFT) applied to tilapia } \\
\text { fingerlings production using } \\
\text { different carbon sources: Emphasis on } \\
\text { commercial applications }\end{array}$ & Aquaculture & México \\
\hline $\begin{array}{l}\text { Muhammad H. Azhar; } \\
\text { Suciyono Suciyono; } \\
\text { Darmawan S. Budi; } \\
\text { Mohammad F. Ulkhaq; } \\
\text { Mai Anugrahwati; Julie } \\
\text { Ekasari. }\end{array}$ & 2020 & $\begin{array}{l}\text { Biofloc-based co-culture systems of Nile tilapia } \\
\text { (Oreochromis niloticus) and redclaw crayfish } \\
\text { (Cherax } \\
\text { quadricarinatus) with different carbon-nitrogen } \\
\text { ratios }\end{array}$ & $\begin{array}{l}\text { Aquaculture } \\
\text { International }\end{array}$ & Indonesia \\
\hline $\begin{array}{l}\text { Godwin Abakari; Guozhi } \\
\text { Luo; Haoyan Meng; Zhang } \\
\text { Yang; Gilbert Owusu- } \\
\text { Afriyie; } \\
\text { Emmanuel O. Kombat; } \\
\text { Elliot H. Alhassan. }\end{array}$ & 2020 & $\begin{array}{l}\text { The use of biochar in the production of tilapia } \\
\text { (Oreochromis niloticus) in a } \\
\text { biofloc technology system - BFT }\end{array}$ & $\begin{array}{c}\text { Aquacultural } \\
\text { Engineering }\end{array}$ & China \\
\hline $\begin{array}{l}\text { Godwin Abakari; Guozhi } \\
\text { Luo; Lina Shao; Yusuf } \\
\text { Abdullateef; } \\
\text { Samuel Jerry Cobbina. }\end{array}$ & 2021 & $\begin{array}{c}\text { Effects of biochar on microbial community in } \\
\text { bioflocs and gut of } \\
\text { Oreochromis niloticus } \\
\text { reared in a biofloc system }\end{array}$ & $\begin{array}{l}\text { Aquaculture } \\
\text { International }\end{array}$ & China \\
\hline $\begin{array}{l}\text { Menaga } \\
\text { Meenakshisundaram; Felix } \\
\text { Sugantham; Charulatha } \\
\text { Muthukumar; Mohana } \\
\text { Sundari Chandrasekar. }\end{array}$ & 2021 & $\begin{array}{c}\text { Metagenomic characterization of biofloc in the } \\
\text { grow-out culture of Genetically Improved } \\
\text { Farmed Tilapia (GIFT) }\end{array}$ & $\begin{array}{l}\text { Aquaculture } \\
\text { research }\end{array}$ & Índia \\
\hline
\end{tabular}

Fonte: Autores (2021). 
Apesar do período de análise ser a partir do ano 2008, é possível perceber que as publicações sobre bioflocos aconteceram com maior frequência a partir de 2017. Apesar de haver publicações de países espalhados por vários continentes, a China destaca-se com a maior parcela de pesquisas relacionadas ao sistema de cultivo em bioflocos.

Os periódicos e a quantidade de artigos sobre bioflocos distribuídos por ano segundo as publicações de revistas científicas da base Web of Science (WOS) e Scopus estão descritas na Tabela 3.

Tabela 3. Quantidade de artigos publicados sobre Bioflocos para produção de tilápia do Nilo.

\begin{tabular}{|c|c|c|c|c|c|c|c|c|c|c|c|}
\hline Periódico & 2008 & 2013 & 2014 & 2015 & 2016 & 2017 & 2018 & 2019 & 2020 & 2021 & Total \\
\hline Acta Scientiarum & 0 & 0 & 0 & 0 & 1 & 2 & 1 & 0 & 0 & 0 & 3 \\
\hline $\begin{array}{l}\text { Aquacultural } \\
\text { Engineering }\end{array}$ & 0 & 1 & 0 & 0 & 1 & 0 & 1 & 2 & 1 & 0 & 6 \\
\hline Aquaculture & 1 & 0 & 1 & 1 & 2 & 3 & 4 & 8 & 8 & 6 & 34 \\
\hline $\begin{array}{l}\text { Aquaculture } \\
\text { international }\end{array}$ & 0 & 0 & 0 & 0 & 0 & 1 & 0 & 2 & 2 & 3 & 8 \\
\hline Aquaculture Research & 0 & 0 & 0 & 0 & 0 & 4 & 5 & 2 & 3 & 1 & 15 \\
\hline $\begin{array}{l}\text { Fish \& Shellfish } \\
\text { Immunology }\end{array}$ & 0 & 0 & 0 & 0 & 0 & 1 & 2 & 1 & 2 & 0 & 6 \\
\hline $\begin{array}{l}\text { Microbial } \\
\text { Biotechnology }\end{array}$ & 0 & 0 & 0 & 0 & 0 & 1 & 0 & 0 & 0 & 0 & 1 \\
\hline $\begin{array}{l}\text { North American Journal } \\
\text { of Aquaculture }\end{array}$ & 0 & 0 & 0 & 1 & 0 & 0 & 0 & 0 & 0 & 0 & 1 \\
\hline Revista Caatinga & 0 & 0 & 0 & 0 & 0 & 1 & 0 & 0 & 0 & 0 & 1 \\
\hline
\end{tabular}

Fonte: Autores (2021).

Outro ponto importante identificado foi quanto à metodologia utilizada por todas as pesquisas estudadas. Percebe-se que os métodos de pesquisa utilizados nos artigos selecionados foram identificados em sua maioria utilizando desenho experimental, quando comparados a artigos de pesquisa bibliográfica e teórica.

Quanto as palavras-chave mais significativas utilizadas como critério de inclusão e exclusão desta pesquisa, percebese, de acordo com a Figura 4, que muitas encontram-se em vários dos artigos selecionados. A palavra-chave que mais se destacou foi biofloc.

Para corroborar na identificação das palavras-chave mais importantes nos artigos selecionados, fez-se uma nuvem de palavras (Clouds, 2020), conforme mostra a Figura 4. 
Figura 4. Nuvem de palavras-chave dos artigos científicos com tema bioflocos.

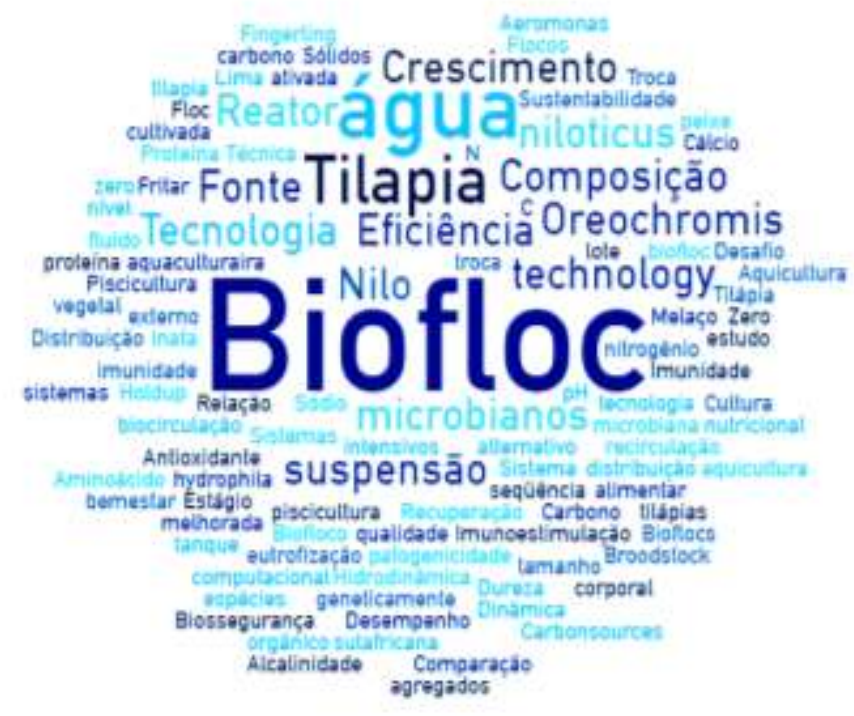

Fonte: Autores (2021).

Azin e Little (2008) avaliaram a tecnologia BFT em tanques com tilápia do Nilo (Oreochromis niloticus) em baixa luminosidade. Os autores verificaram uma taxa de sobrevivência de $100 \%$, ou seja, sem mortalidade. Além disso, perceberam que é possível reduzir o percentual de proteína na ração de peixes criados em sistema bioflocos sem que ocorra diferença significativa no crescimento dos animais, o que demonstra haver aproveitamento do material floculado como alimento complementar pelos animais. Os indicadores de bem-estar também foram comparados e não foram registradas diferenças significativas entre BFT e tanques de controle, indicando que não houve aumento do estresse do peixe devido à presença de bioflocos. Outra constatação foi de que o peso final individual dos peixes criados em bioflocos foi 9-10\% maior que no tratamento controle e a produção líquida de peixe foi $45 \%$ maior nos tanques BFT do que nos tanques de controle.

Luo et al. (2013) buscaram compreender as reações de nitrogênio (N) inorgânico em um reator em batelada de seqüenciamento utilizando BFT com o objetivo de tratar sólidos em suspensão (SS) oriundos de outro sistema de produção de peixes. Os resultados mostraram que o amônio liberado dos sólidos em suspensão foi assimilado por bactérias heterotróficas para formar bioflocos com adições suficientes de uma fonte de carbono, ou seja, as reduções acentuadas de amônio e nitrato encontradas possuem potencial em reduzir contaminantes em águas de criações de peixes em sistema BFT, sendo um promotor de sustentabilidade ambiental.

Ekasari et al. (2014) analisaram se a composição nutricional do bioflocos estava relacionada com o tamanho de partículas do mesmo e constataram que a classe de bioflocos de maior dimensão $(100 \mu \mathrm{m})$ continha os maiores níveis de proteína $(27,8 \%)$ e lipídios $(7,5 \%)$. Já aquele de dimensão média $(48 \mu \mathrm{m})$ possui uma riqueza maior em aminoácidos essenciais, além de efetivamente recuperar melhor o nitrogênio disponível no ambiente aquático, demonstrando serem ótimas fontes de nutrientes para animais aquáticos como tilápia e outros. Ao conseguir recuperar melhor o nitrogênio da água, há redução da contaminação da mesma e, consequentemente, melhores desempenhos no sistema produtivo permitindo tanto uma melhoria ambiental como econômica.

Long et al. (2015), avaliaram os efeitos do cultivo de tilápias em sistema BFT sobre o crescimento, atividade digestiva, hematologia e resposta imune. Os autores indicaram que o BFT pode melhorar os índices zootécnicos, o desempenho das enzimas digestivas e a resistência do sistema imunológico das tilápias geneticamente modificadas (GIFT), sendo um ótimo indicador na prevenção ou redução de doenças. Esta afirmativa permite verificar a potencialidade de redução 
do fornecimento de ração aos animais aquáticos sem prejudicar no balaço nutricional ideal aos animais, reduzir a conversão alimentar e, consequentemente, reduzir a pressão por mais áreas que seriam utilizadas para plantar e produzir alimentos, já que estes índices auxiliam no desempenho econômico e ambiental da atividade.

López-Elías et al. (2015) verificaram que a substituição de farinha de peixe por farinha de vegetais na ração peletizada não teve efeito adverso na resposta à produção de tilapia vermelha cultivada em água salgada no sistema de bioflocos com diferentes dietas. Portanto, ingredientes alternativos na composição da ração pode reduzir os custos com elaboração de alimentos para animais aquáticos e, consequentemente, aumentar a eficência econômica nos sistemas produtivos intensivos.

Estudos de Ekasari et al. (2015) estudaram a criação de larvas de tilápia em ambiente BFT (melaço com 53\% de carbono, numa relação de C:N de 10/1) e em sistema convencional de cultivo (controle). A sobrevivência das larvas criadas em BFT foi maior (90-98\%) do que no tratamento controle (67-75\%) e há uma maior uniformidade nas larvas criadas em BFT. Além disso, o sistema BFT proporcionou maior sobrevivência dos animais (75-80\%) quando infectados patologicamente por Streptococcus agalactiae em relação ao tratamento controle (55\%). Esses pesquisadores realizaram também um teste de estresse por salinidade e as larvas criadas em BFT tiveram sobrevivência de 72\% e 42\% em 1 h e 24 h, respectivamente, após o estresse de salinidade, sendo este um resultado significativamente maior do que para as larvas de origem do tratamanto controle, que mostraram uma sobrevivência de $33 \%$ e 5\% nestes respectivos momentos. Estes resultados indicam que a tecnologia (BFT) pode proporcionar desempenhos zootécnicos superiores durante a larvicultura em comparação aos sistemas convencionais de criação de peixes, o que incide em melhorias no desempenho econômico da atividade.

Day, Salie e Stander (2016) enfatizam na flexibilização ou exceções das normas ambientais quando se trata de sistemas fechados de criação de animais aquáticos (sistemas que não despejam água de volta aos recursos hídricos naturais). No estudo em questão, os autores pesquisaram o desempenho de diferentes espécies de peixes permitidas para o cultivo na região, inclusive tilápia (Oreochromis niloticus), todas elas criadas em BFT. Os resultados enfatizam o bom desempenho zootécnico de Oreochromis niloticus em sistemas bioflocos de produção, justamente devido a redução do consumo de ração para produzir proteína de alto valor nutricional, o que proporciona melhorias econômicas e reduz as pressões por mais áreas de plantio dos ingredientes utilizado nas rações.

Zhu et al. (2016) avaliaram a especificidade do tamanho ideal da bolha de oxigenação e o Tempo de Retenção Hidráulica (TRH) para a uniformidade da distribuição de bioflocos em um sistema BFT por meio do método de Dinâmica dos Fluidos Computacional (CFD). Os autores perceberam que para manter uma melhor homogeneização do bioflocos na água, a espessura da bolha de oxigenação deve ficar entre $1 \mathrm{~mm}$ e $2 \mathrm{~mm}$ e a TRH deve se manter baixa $(0,45 \mathrm{~h})$. Nesse sentido, foi possível perceber a importância de se manter a homogeneidade do ambiente aquático para evitar problemas como sedimentação dos sólidos totais suspensos, uma vez que este cuidado técnico auxilia no sucesso econômico da atividade.

Pérez-Fuentes et al. (2016), utilizando melaço como fonte de carbono, analisaram diferentes proporções na relação C:N na criação de tilápia e concluíram que a taxa de sobrevivência dos peixes criados em BFT foi de $10 \%$ a mais que o tratamento controle (sistema convencional). A produção total foi maior na relação $\mathrm{C}: \mathrm{N}$ de 10:1 em relação às outras proporções e a qualidade da água permaneceu similar entre os tratamentos. Os autores enfatizaram ainda que a tecnologia de BFT é uma ótima alternativa para produção de proteína animal aquática, principalmente onde a alcalinidade da água é um fator limitante. Os resultados corroboram com a afirmação de que BFT contribui para otimizar a utilização dos recursos naturais e proporcionar melhor desempenho econômico.

Silva et al. (2016) isolaram e identificaram os principais grupos bacterianos existentes na criação de tilápia na fase juvenil na presença de bioflocos ou perifíton e o seu potencial patogênico. Com resultado, esses autores identificaram que os tratamentos com bioflocos e perifíton ou só perifiton possuíam bactérias com menor potencial patogênico em relação aos outros tratamentos. Além disso, o ganho de peso final foi maior no tratamento com bioflocos e perifíton em comparação aos 
outros tratamentos. Estes resultados podem ser devido ao aumento da diversidade de microrganismos no ambiente aquático, permitindo uma maior competitividade entre bactérias patogênicas e não patogênicas. Portanto, o uso de sistemas que permitam menor potencial patogênico ou maior resistência às doenças pelos animais podem evitar problemas ambientais e ainda melhorar os desempenhos produtivos.

Bossier e Ekasari (2017) realizaram uma revisão de literatura sobre o tema "bioflocos" e concluíram que a aplicação de BFT proporciona vantagens para a aquicultura ao ponto de contribuir para a efetivação dos objetivos de desenvolvimento sustentável. Esses autores sustentam essa afirmativa ao ressaltarem a redução de resíduos nitrogenados e fósforo liberados na natureza devido a atividade induzida por microrganismos heterotróficos que convertem esses resíduos em nutrientes úteis aos animais aquáticos cultivados nesse sistema. Entretanto, os autores concluem que a aplicação da tecnologia proporciona maior produtividade com impacto ambiental reduzido e que é preciso realizar mais pesquisas para compreendermos melhor sobre a otimização do sistema.

Haridas et al. (2017) analisaram aspectos imunofisiológicos de tilápia em BFT e constataram que, mesmo após contaminação biológica proposital, nas diferentes densidades de estocagem testadas, houve maiores taxas de sobrevivência dos peixes criados em BFT em comparação ao tratamento controle. Esta informação permite entender que a dinâmica biológica no BFT proporciona uma maior sobrevivência dos peixes às contaminações biológicas, assim como melhorias na eficiência do sistema imunológico. Os autores observaram ainda que a faixa ideal de densidade fica entre $200-250$ larvas.m ${ }^{-3}$, mas densidades maiores (até 350 larvas. $\mathrm{m}^{-3}$ ) ainda permitem taxas de sobrevivências maiores do que em sistemas convencionais de cultivo. Isso permite enfatizar o potencial de melhorias nos desempenhos zootécnicos de cultivo para o mesmo volume de água, o que gera ganhos de produtividade.

Martins et al. (2017) avaliaram a alcalinidade da água utilizando bicarbonato de sódio $\left(\mathrm{NaHCO}_{3}\right)$, carbonato de cálcio $\left(\mathrm{CaCO}_{3}\right)$ ou hidróxido de cálcio $\left(\mathrm{Ca}(\mathrm{OH})_{2}\right)$ em BFT e concluiram que todos os tratamentos são eficazes na correção da alcalinidade, porém, com o bicarbonato de sódio o pH ficou um pouco mais elevado. Além disso, ocorreu um maior crescimento e rendimento líquido com o uso de $\mathrm{NaHCO}_{3}$ e $\mathrm{Ca}(\mathrm{OH})_{2}$, proporcionando um melhor desempenho econômico. Nesse sentido, demonstra-se a complexidade técnica do sistema e pôde ser indicando qual o produto que melhor ajusta a alcalinidade do sistema, variável importante no desempenho produtivo e econômico da atividade.

Alves et al. (2017) pesquisando sobre os efeitos da transferência para BFT em diferentes momentos da tilápia do Nilo, sugerem que os alevinos de 1,4g até aproximadamente $20 \mathrm{~g}$ já podem ser alocados no $\mathrm{BTF}$, pois não há comprometimento no índice de sobrevivência ou no peso médio dos peixes. Os resultados apontaram um ganho de peso diário de $0,59 \mathrm{~g}$, atingindo as expectativas dos pesquisadores. Estes resultados demonstram que é possível criar a $O$. Niloticus desde tamanhos muito pequenos em sistemas BFT, sem que ocorra prejuízos nos desempenhos zootécnicos. Informações técnicas como esta permitem o sucesso econômico da atividade.

Mansour e Esteban (2017) avaliaram a eficácia de diferentes tratamentos com BFT para compensar a redução do nível de proteína. Seis grupos foram estabelecidos e alimentados com a mesma dieta à base de plantas contendo 20 ou $30 \%$ de proteína bruta: dois grupos em condições de águas claras e sem fontes adicionais de carbono, dois grupos de bioflocos que receberam uma moagem a base de subprodutos de trigo como fonte adicional de carbono e dois grupos de bioflocos receberam farelo de arroz. O subproduto à base de trigo apresentou-se como melhor fonte de carbono combinado com uma alimentação de apenas $20 \%$ de proteína. Portanto, a potencial diminuição da proteína na ração influencia na redução dos custos com alimentação, auxiliando economicamente e ambientalmente a atividade produtiva.

Ahmad et al. (2017) descrevem em revisão bibliográfica os principais benefícios e aceitações sobre o uso do bioflocos, enfatizando a renovação mínima ou quase nula de água no sistema, a redução da quantidade de proteína na ração em aproximadamente $50 \%$ e diminuição da eutrofização e/ou degradação do meio aquático causados por excreções dos animais na 
água. Os autores concluiram que o sistema BFT ajuda na redução da contaminação ambiental de áreas para plantio dos ingredientes das rações e custos de produção, proporcionando melhorias ambientais e econômicas.

Silva et al. (2017) avaliaram a utilização de melaço, açúcar e amido de mandioca, bem como a relação C:N (10:1 e 20:1), nos custos de produção de cada fonte de carbono. Os resultados apontaram que o amido de mandioca apresentou maior custo (US\$ 1.14. $\mathrm{kg}^{-1}$ ) e menor disponibilidade de fonte de carbono. O açúcar apresentou um custo de US\$ $0.42 . \mathrm{kg}^{-1} \mathrm{e}$ o melaço apresentou menor custo (US\$ $0.25 . \mathrm{kg}^{-1}$ ). Fonte de carbono como o melaço possui um grande potencial de redução de custos em BFT. Contudo, deve-se atentar que esses valores dependem da disponibilidade do subproduto em cada região. Uma vez disponível e com valores acessíveis, esses produtos podem proporcionar a redução dos custos desta tecnologia e possibilitar melhorias no desempenho econômico do sistema de produção.

Cavalcante et al. (2017) determinaram o efeito da restrição alimentar no aproveitamento do alimento natural em três diferentes sistemas de cultivo (águas verdes, bioflocos e biofíton) e seu possível prejuízo zootécnico. Os autores observaram uma redução na concentração de amônia e nitrito (elementos tóxicos aos peixes) na água com bioflocos e concluíram que uma redução alimentar de $15 \%$ afeta o desempenho do animal apenas em sistemas convencionais (tratamento controle) de produção. O potencial dessa tecnologia reside, dentre outras coisas, em reduzir as altas concentrações de elementos contaminantes na água, assim como uma melhora na conversão alimentar dos animais cultivados, diminuição dos custos com alimentação, redução na pressão por novas áreas de terra para produzir alimentos para peixes, além de melhorar os dados econômicos da atividade.

Tubin et al. (2019) avaliaram níveis de inclusão de 0, 5, 10, 15 e 20\% da farinha das larvas de inseto Tenebrio molitor em dietas para tilápia criada em sistemas de bioflocos. Neste estudo, os autores indicaram até $10 \%$ de nível de inclusão de farinha de T. molitor em dietas para juvenis de tilápia, proporcionando um ótimo desempenho zootécnico dos peixes e a diversificação de microrganismos no sistema BFT.

Manduca et al. (2020) verificaram os efeitos de diferentes densidades de estocagem entre 20, 40, 60 e 80 peixes. $\mathrm{m}^{-3}$ de juvenis de tilápia do Nilo sobre qualidade da água, desempenho de crescimento, composição corporal, morfometria branquial e bioquímica sanguínea dos peixes criados em sistema BFT de troca zero de água. O estudo demonstrou que o desempenho zootécnico dos peixes em densidades de estocagem de 20 e 40 indivíduos. $\mathrm{m}^{-3}$ foi superior aos demais, especialmente para ganho de peso diário e taxa de sobrevivência. O modelo de regressão quadrática para densidade de estocagem indicou o uso de 51,79 peixes. $\mathrm{m}^{-3}\left(13 \mathrm{~kg} \cdot \mathrm{m}^{-3}\right)$ como o máximo para a biofloco de troca zero de água, mantendo as variáveis fisiológicas e a homeostase dos peixes para ótimo crescimento.

Luo et al. (2021) verificaram o efeito do biochar (tipo de carvão vegetal obtido por meio de pirólise) e sua influência na comunidade microbiana dos bioflocos e no intestino de $O$. niloticus criados em um sistema BFT. Os autores inferiram que as comunidades bacterianas do sistema de cultivo eram abundantes e diversas quando comparadas à comunidade intestinal dos peixes criados em sistemas de bioflocos. Além disso, foi possível notar que o uso de diferentes fontes de carbono podem influenciar a estrutura da comunidade bacteriana tanto nos bioflocos quanto no intestino dos animais.

\section{Considerações Finais}

A sustentabilidade econômica, social e ambiental em sistemas de produção de peixes através da tecnologia bioflocos, especificamente para a espécie Oreochromis niloticus, envolve o desenvolvimento técnico e manejo adequado. A maioria dos trabalhos selecionados nessa metanálise aprofundou as pesquisas nas técnicas de cultivo e conseguiu relacionar com fatores referentes aos custos de produção e desempenho zootécnico, os quais estão intimamente ligados ao desenvolvimento econômico da atividade. Porém, nenhum trabalho conseguiu mostrar de que forma a tecnologia pode proporcionar um desenvolvimento social, impedindo de afirmar sua inserção no tripé do desenvolvimento sustentável. 
Deste modo, propõem-se, para futuros estudos, o levantamento da produção englobando o tripé da sustentabilidade de forma abrangente, possibilitando ressaltar a importância da tecnologia como uma alternativa de atividade economicamente viável, ambientalmente correta e socialmente justa.

\section{Referências}

Ahmad, I., Rani, A. M. B., Verma, A. K. \& Maqsood, M. (2017). Biofloc technology: an emerging avenue in aquatic animal healthcare and nutrition. Aquaculture International, 25, 1215-1226.

Alves, G. F. O., Fernandes, A. F. A., Alvarenga, E. R., Turra, E. M., Sousa, A. B. \& Teixeira, E. A. (2017). Effect of the transfer at different moments of juvenile Nile tilapia (Oreochromis niloticus) to the biofloc system in formation. Aquaculture, 479, 564-570.

Avnimelech, Y. (1999). Carbon/nitrogen ratio as a control element in aquaculture systems. Aquaculture, 176, $227-235$.

Avnimelech, Y. (2007). Feeding with microbial flocs by tilapia in minimal discharge bio-flocs technology ponds. Aquaculture, $264,140-147$.

Avnimelech, Y. (2009). Biofloc Technology — A Practical Guide Book. The World Aquaculture Society, 182.

Azim, M.E. \& Little, D. C. (2008). The bioflocs technology (BFT) in indoor tanks: water quality, bioflocs composition, and growth and welfare of Nile tilapia (Oreochromis niloticus). Aquaculture, 283, 29-35.

Bossier, P. \& Ekasari, J. (2017). Biofloc technology application in aquaculture to support sustainable development goals. Microbial Biotechnology, 10(5), 1012-1016.

Cavalcante, D. H., Lima, F. R.S., Rebouças, V. T. \& Carmo e Sá, M. V. (2017). Nile tilapia culture under feeding restriction in bioflocs and bioflocs plus periphyton tanks Cultura de tilapia do Nilo sob restrição de alimentação em bioflocs e bioflocs mais tanques de perifita. Acta Scientiarum. Animal Sciences, $39(3), 223-228$.

Crab, R., Defoirdt, T., Bossier, P., \& Verstraete, W. (2012). Biofloc technology in aquaculture: beneficial effects and future challenges. Aquaculture, 356, $351-356$.

Day, S. B., Salie, K. \& Stander, H. B. (2016). A growth comparison among three commercial tilapia species in a biofloc system. Aquaculture International, 24, 1309-1322.

Ekasari, J., Angela, D., Waluyo, S. H., Bachtiar, T., Surawidjaja, E. H., Bossier, P., De Schryver. P. (2014). The size of biofloc determines the nutritional composition and the Nitrogen recovery by aquaculture animals. Aquaculture, 426-427, 105-111.

Ekasari, J., Azhar, M.H., Surawidjaja, E.H., Nuryati, S., De Schryver, P., \& Bossier, P. (2014). Immune response and disease resistance of shrimp fed biofloc grown on different carbon sources. Fish and Shellfish Immunology, 41, 332-339.

Ekasari, J., Rivandi, D. R., Firdausi, A. P., Surawidjaja, E. H., Bossier, P. \& De Schryver, P. (2015). Biofloc technology positively affects Nile tilapia (Oreochromis niloticus). Aquaculture, 441, 72-77.

Fachin, O. (2006). Fundamentos de metodologia. (5a ed.), Saraiva.

FAO - Food and Agriculture Organization of the United Nations. (2019). The state of food security and nutrition in the world.

Galvão, T. F. \& Pereira, M. G. (2014). Revisões sistemáticas da literatura: passos para sua elaboração. Epidemiologia e Serviços de Saúde, Brasília, 23(1), $183-184$.

Haridas, H., Verma, A. K., Rathore, G., Prakash, C., Sawant, P. B. \& Rani, A. M. B. (2017). Enhanced growth and immuno-physiological response of Genetically Improved Farmed Tilapia in indoor biofloc units at different stocking densities. Aquaculture Research, 48, 4346-4355.

Jorge A. Pérez-Fuentes, J. A., Hernández-Vergara, M. P., Pérez-Rostro, C. I. \& Fogel, I. (2016) C:N ratios affect nitrogen removal and Production of Nile tilapia Oreochromis niloticus raised in a biofloc system under high density cultivation. Aquaculture, 452, $247-251$.

López-Elías, J. A., Moreno-Arias, A., Miranda-Baeza, A., Martínez-Córdova, L. R., Rivas-Vega, M. E. \& Márquez-Ríos, E. (2015). Proximate composition of bioflocs in culture systems containing hybrid red tilapia fed diets with varying levels of vegetable meal inclusion. North American Journal of Aquaculture, 77(1), 102-109.

Luo, G. Avnimelech, Y., Pan, Y. \& Tan, H. (2013). Inorganic nitrogen dynamics in sequencing batch reactors using biofloc technology to treat aquaculture sludge. Aquacultural Engineering, 52, 73-79.

Manduca, L. G., da Silva, M. A., de Alvarenga, É. R., de Oliveira Alves, G. F., de Araújo Fernandes, A. F., Assumpção, A. F., \& Turra, E. M. (2020). Effects of a zero exchange biofloc system on the growth performance and health of Nile tilapia at different stocking densities. Aquaculture, 735064 .

Mansour, A. T. \& Esteban, M. A. (2017). Effects of carbon sources and plant protein levels in a biofloc system on growth performance, and the immune and antioxidant status of Nile tilapia (Oreochromis niloticus). Fish and Shellfish Immunology, 64, 202-209.

Martins, G. B., Tarouco F., Rosa, C. E. \& Robaldo, R. B. (2017). The utilization of sodiumbicarbonate,calciumcarbonateorhydroxidein biofloc system: waterquality, growth performance andoxidative stress of Nile tilapia (Oreochromis niloticus). Aquaculture, 468, 10-17.

Pasco, J J. M. (2015). Aeração em cultivos superintensivos de tilápias Oreochromis niloticus, em bioflocos e com troca mínima de água. Tese apresentada ao Programa de PósGraduação em Aquicultura da Universidade Federal de Santa Catarina. 120p. 
Research, Society and Development, v. 10, n. 5, e56910515200, 2021

(CC BY 4.0) | ISSN 2525-3409 | DOI: http://dx.doi.org/10.33448/rsd-v10i5.15200

Pérez-Fuentes, A., Perez-Rostro, C.I. \& Hernandez-Vergara, M. (2013). Pond-reared Malaysian prawn Macrobrachium rosenbergii with the biofloc system. Aquaculture, 400, 105-110.

Richardson, R. J. (1999). Pesquisa Social: métodos e técnicas. Atlas.

Silva, J. L. S. da, Cavalcante, D. H., Carvalho, F. C. T. de, Vieira, R. H. S. F., Carmo e Sá, M. V. \& Sousa, O. V. de. (2016). Aquatic microbiota diversity in the culture of Nile tilapia (Oreochromis niloticus) using bioflocs or periphyton: virulence factors and biofilm formation. Acta Scientiarum. Animal Sciences, $38(3), 233-241$.

Silva, U. L., Falcon, D. R., Pessôa, M. N. C. \& Correia, E. S. (2017) Carbon sources and C:N ratios on water quality for Nile tilapia farming in Biofloc System. Revista Caatinga, 30(4), 1017-1027.

Tubin, J. S. B., Paiano, D., de Oliveira Hashimoto, G. S., Furtado, W. E., Martins, M. L., Durigon, E., \& Emerenciano, M. G. C. (2019). Tenebrio molitor meal in diets for Nile tilapia juveniles reared in biofloc system. Aquaculture, 734763.

Zhua, S. M., Shia, M. M., Yun, Y. J., Guoa, X. S, Yea, Z. Y. Hana, Z. Y., Denga, Y. L. \& Liuaa, G. (2016). Applications of computational fluid dynamics to modeling hydrodynamics in tilapia rearing tank of Recirculating Biofloc Technology system. Aquacultural Engineering, 74, 120-130. 